\title{
RELENDO LURIA: OS LIMITES DE UMA PERSPECTIVA
}

\author{
MARISOLBARENCO DE MELLO \\ Programa de Pós-Graduação em Educação da Universidade Federal Fluminense
}

\section{RESUMO}

Com o objetivo de discutir a relação existente entre a escrita e o desenvolvimento cognitivo de sujeitos adultos não alfabetizados, realizamos uma (re)leitura da pesquisa de Luria, tradicional no universo dos estudos cognitivos. Interessa-nos esclarecer algumas das noções historicamente estabelecidas por esses estudos que, baseados nos critérios da lógica formal, apontam déficits cognitivos em sujeitos adultos não alfabetizados. Como um de seus resultados, a presente análise aponta para a necessidade de uma ruptura com os critérios tradicionalmente estabelecidos, centrados principalmente na lógica formal, e propõe uma visão plural da racionalidade humana, levando-se em conta as interações dos sujeitos entre si e com a cultura na qual estão inseridos e que modificam, em suas existências. Este trabalho é assim parte de um estudo mais amplo que se propõe a olhar para as racionalidades de sujeitos com diversos niveis de letramento, em uma situação dialógica, tendo-se como pressuposto fundamental, construído com base na releitura de Luria, entender as racionalidades como intimamente relacionadas às vivências e práticas culturais dos sujeitos.

ALFABETIZAÇÃO DE ADULTOS - LINGUAGEM - CULTURA - RACIONALIDADE

\section{ABSTRACT}

READING LURIA: THE LIMITATIONS OF A PERSPECTIVE. With the aim of discussing the relationship between writing and the cognitive development of illiterate adults, we carried out a (re)reading of Luria's research, a central reference among cognitive studies. Our main purpose was to clarify some of the historically established notions that underpin those studies, which focus on criteria from formal logic and show illiterate adults' cognitive deficits. Our analysis stresses the need, among other findings, to break away from traditionally established criteria that rely on formal logic. As a result, our study proposes a plural view of human rationality, that considers subjects' interactions among themselves and with the culture to which they belong, and which they modify throughout their lives. This study is part of a broader project which further develops our analysis of Luria's study. Starting from the assumption that rationalities are intimately linked to peoples' experiences and practices in culture, this project proposes to look at the rationalities of subjects at different levels of litteracy, when involved in a dialogic situation.

Texto oriundo de um capítulo da dissertação de mestrado intitulada $A$ multiplicidade das formas de ser racional: escrita e racionalidade, orientada pela professora Dominique Colinvaux e aprovada pelo Programa de Pós-graduação da Universidade Federal Fluminense em março de 1998. 


\section{INTRODUÇÃO}

Em outra época da história da humanidade o céu sobre as nossas cabeças era outro. Não pela própria historicidade do espaço, mas por uma outra forma de ser visto. A imensidão povoada de estrelas era então uma dimensão que, por analogia, assemelhava-se a tudo que rodeava o ser humano. Macrocosmo e microcosmo formavam um sistema global de correspondências, regido pelo princípio construtor da imitação. Com o olhar, que buscava as infinitas similitudes, ervas, animais, sementes, estrelas, seres humanos e linguagens aproximavam-se e, nessas duplicações reflexivas, o universo era revelado de forma paciente e sempre provável. Nesse tempo, arte e magia coloriam o conhecimento, e era possível haver o encontro entre um ser humano que nasce e a conjuntura dos astros, num instante - não mais que o cintilar de um instante marcado pelas similitudes.

Mas essa época foi banida de nossas referências como algo de que precisamos esquecer, se é que queremos ser "sérios". E a outra época que começou então veio modificar qualquer forma de ser, fazer, pensar, dizer, conhecer, que não fosse aquela eleita e tornada absoluta. Começara a modernidade, e as estrelas já não eram mais as mesmas...

Isso é o que conta a história. A mesma, segundo a qual, dentre outros, foi Descartes quem lançou as sementes das quais nosso pensamento já tem as frutas mais que maduras. O modelo cartesiano, que se tornaria a própria ordem científica, rompeu com as semelhanças; não as negando totalmente, mas sim universalizando a comparação, e a elevando ao estatuto do próprio conhecimento. As hierarquias analógicas deram lugar, "confusas e imprecisas" que eram, à análise por comparação. A semelhança poderia ser admitida, desde que atingisse a perfeita certeza, submetida às provas das duas únicas formas de comparar: a medida e a ordem - que determinam as unidades fundamentais e analisam o semelhante conforme identidades evidentes e diferenças que vão do simples ao complexo.

A partir daí a diferença encontra o lugar antes destinado à similitude. É a época da criação do outro, aquele que se distingue do próprio. Formas outras de ser, pensar, dizer, fazer, conhecer são comparadas e analisadas segundo o que lhes falta, marcadas com o signo da diferença e que, postas numa escala ordenada, representam faltas, já que o sistema é finito; seu fim: o próprio, eleito como critério de racionalidade e subjetividade.

Mas isso é o que conta a história. O que ela não conta é que o "sonho" moderno da universalidade não mais se sustenta. Mesmo quando foi crença, o era de um grupo restrito de sábios e doutos. Talvez nem todos os seres humanos tenham se tornado modernos, ou alguns possam ter escapado da formatação total ao modelo cartesiano. Dadas as formas de poder instituídas e, como as culturas e os seres humanos se criam mutuamente, temos que ter em mente que, culturalmente, pelo menos em alguma proporção, somos todos 
modernos. Mas, por ser nossa cultura ocidental classificatória, ela é excludente; e se alguns seres humanos foram excluídos, talvez tenham escapado às tecnologias formatadoras dos seres, fazeres, dizeres e das formas de conhecer. A estes que permaneceram, para a história, no lugar "limítrofe" que lhes foi destinado pelas comparações é que queremos lançar nosso olhar. Um olhar que, como diria Benjamin (1994), "escove a história a contrapelo" e potencialize esses sujeitos como produtores contemporâneos da cultura, portanto herdeiros e fazedores também de nossas heranças.

O texto que segue esta introdução trata de um dos representantes da "lógica do próprio": Luria ( 1990), e seu trabalho Desenvolvimento cognitivo: seus fundamentos culturais e sociais, realizado na ex-União Soviética, nos anos de 193 I a 1932, com adultos (na sua maioria não alfabetizados) de vilarejos e terras de pastoreio das regiões do Uzbequistão e Kirghizia.

Não sabemos como os sujeitos da pesquisa de Luria enxergavam as estrelas; sabemos somente que foram comparados, analisados e avaliados como sujeitos que apresentavam déficits de diversas ordens, porque sua lógica não era a do próprio. Eram, portanto, o outro. Talvez lançando um olhar para os "fósseis" de suas falas - marcas deixadas no livro escrito pelo pesquisador - possamos encontrar algumas pistas que nos ajudem a compreender as "secretas" lógicas não consideradas pelo "herói moderno". ' Aquele que com sua mais poderosa arma - os signos monovalentes -, trata de apagar os vestígios das possibilidades de ser também, assinalando o diferente com a alcunha do outro.

Talvez o que possamos fazer aqui é simplesmente tentar restaurar em nosso olhar o cintilar das similitudes e, relendo os escritos, buscar aproximar entre si seres humanos, linguagens, lógicas e conhecimentos, enxergando as possibilidades de ser, ao mesmo tempo, diverso e contemporâneo, que neles são reveladas. Para além disso, nossa intenção é a de contribuir para a construção de uma utopia: uma época em que os olhares possam ser livres para enxergar as estrelas de forma múltipla e paciente, permitindo as trocas dialogais de múltiplos pontos de vista.

Com o objetivo de analisar a formação sócio-histórica dos processos mentais de grupos de sujeitos na ex-União Soviética, Luria (1990) descreve algumas entrevistas, sob

I. Apesar de termos consciência de que os objetivos de Luria eram, conforme contextualizamos em nossa dissertação, os de contribuir para uma visão "positiva" do processo necessário, para a época, da escolarização de massa, entendemos que seja pertinente a revisão dos seus pressupostos, uma vez que tudo que afirma, nega; e o que Luria diz, silencia outras formas possíveis. Sendo Luria uma referência ainda presente nos estudos cognitivos, consideramos pertinente a análise crítica que, longe de desmerecer o pesquisador, pretende tão-somente contribuir com mais uma visão possível. 
forma de "diálogos", entre um entrevistador de sua equipe de pesquisadores e sujeitos não alfabetizados.

O que pretendemos aqui é retomar algumas partes da pesquisa de Luria, procurando fazer uma releitura de algumas entrevistas que serviram de base para este artigo.

Chamou-nos a atenção em particular a complexidade das respostas dos entrevistados: adultos não alfabetizados, em contraste com a posição do entrevistador, que as avaliou como uma não competência em termos cognitivos. As entrevistas foram retiradas dos capítulos "Dedução e Inferência" e "Generalização e Abstração", e vão ser relidas fora de ordem, objetivando a compreensão de alguns aspectos dos quais tratamos. Entre os aspectos escolhidos, incluem-se a metodologia utilizada no estudo, a influência da cultura nos enunciados discursivos dos sujeitos participantes da pesquisa, e as lógicas que são reveladas nos atos de fala.

O paradigma que nos guia nesta releitura é o indiciário(Ginzburg, | 199 |), na busca de pistas que ajudem a compreender tanto a complexidade das respostas dos sujeitos quanto as lógicas que são reveladas, no momento do confronto com a lógica do pesquisador. Acreditamos que nas falas desses sujeitos há indícios de uma lógica própria, não estritamente a formal - que o pesquisador buscava encontrar. Pensamos que essa lógica que os sujeitos nos revelam é resultado de uma forma específica de organizar o real, considerando-se a historicidade das relações entre os sujeitos e suas culturas.

Vamos procurar, nas entrevistas relatadas, os indícios que nos levem a compreender as posições que os sujeitos - entrevistadores e entrevistados - assumem, no momento do confronto dialógico, bem como as lógicas diversas que ali são confrontadas. Trabalhamos, como hipótese, de acordo com Bakhtin (1 992), que as posições dos sujeitos nas culturas e suas formas de organizar o real ${ }^{2}$ são integradas.

Selecionamos três entrevistas em particular, a de Abdurakhm e as de dois outros sujeitos, Khamrak e Rustam, pela riqueza de indícios que oferecem. Incluímos também fragmentos das entrevistas de outros quatro sujeitos, Sher, Kar Farfil, Yarb Madmar e Mad Suleim, que, acreditamos, possam contribuir para uma melhor compreensão de algumas noções emergentes nas três primeiras entrevistas.

\section{A PALAVRA}

O que trazemos inicialmente para a análise é uma parte da pesquisa de Luria, na qual este procura investigar os processos inferenciais, com base na da solução de

2. Trabalhamos com a expressão "formas de organizar o real" no sentido de que o real é organizado, pelos sujeitos, por critérios racionais, que acreditamos estarem intimamente relacionados com suas vivências, relações e práticas culturais. 
silogismos. No tópico "O Processo de Dedução", Luria (1990, p. | 42) apresenta aos sujeitos dois silogismos, um contendo premissas familiares às suas experiências, outro com material não familiar. Em ambas as situações, espera-se que as inferências sejam feitas de maneira teórica.

O silogismo, com conteúdo não familiar à experiência dos sujeitos, foi:

No norte, onde há neve, todos os ursos são brancos.

Novaya Zemlya fica no norte.

De que cor são os ursos lá?

A seguir, transcrevemos a entrevista de um dos sujeitos (Abdurakhm), para uma releitura. Na transcrição das entrevistas Luria põe entre parênteses a sua avaliação a respeito das respostas dadas pelos entrevistados. [S] é o sujeito e [E] o entrevistador.

Sujeito: Abdurakhm, trinta e sete anos, de um vilarejo isolado de Kashgar, analfabeta.

O seguinte silogismo é apresentado: No Norte, onde há neve, todos os ursos são brancos. Novaya Zemlya fica no norte e lá sempre neva. De que cor são os ursos lá? S: Há diferentes tipos de ursos.

(Falha em inferir a partir do silogismo)

O silogismo é repetido.

S: Eu não sei; eu já vi um urso negro, eu nunca vi outros... Cada localidade tem seus próprios animais: se é branco, eles serão brancos; se for amarelo, eles serão amarelos.

(Apela somente para a experiência pessoal, gráfica).

E: Mas que tipo de ursos existem em Novaya Zemlya?

S: Nós sempre falamos somente sobre o que já vimos; nós não falamos sobre o que não vimos.

(O mesmo)

E: Mas o que minhas palavras implicam? O silogismo é repetido.

S: Bem, é assim: nosso czar não é como o seu e o seu não é como o nosso. Suas palavras somente podem ser respondidas por alguém que esteve lá, e se uma pessoa não esteve lá ela não pode dizer nada baseada em suas palavras.

(O mesmo)

E: Mas com base nas minhas palavras - no norte, onde há sempre neve, os ursos são brancos - você pode entender que tipo de ursos existem em Novaya Zemlya?

S: Se um homem de sessenta ou oitenta anos tivesse visto um urso branco e tivesse contado sobre isso, se acreditaria nele, mas eu nunca vi um e, portanto, não posso dizer. Esta é minha última palavra. Aqueles que viram podem dizer e aqueles que não viram não podem dizer nada! (Neste ponto um jovem uzbek disse espontaneamente: De suas palavras significa que lá os ursos são brancos). 
E: Bem, qual de vocês está certo?

S: Aquilo que o galo sabe fazer ele faz. Aquilo que eu sei, eu digo, e nada além disso! (Luria, 1990, p. 144-5)

Lendo a entrevista transcrita, parece que Abdurakhm, desde o início, foi capaz de responder à pergunta do silogismo, quando diz: "Eu não sei; eu já vi um urso negro, eu nunca vi outros... Cada localidade tem seus próprios animais: se é branco, eles serão brancos, e se for amarelo, serão amarelos".

Quando fala, "se é branco, eles serão brancos", Abdurakhm responde ao silogismo. E vai mais além, complementando o raciocínio, dando mais um exemplo, e assim, realizando duasinferências logicamente corretas: "se for amarelo, eles serão amarelos".

Num outro momento, responde novamente: "Se um homem de sessenta ou oitenta anos tivesse visto um urso branco e tivesse contado sobre isso, se acreditaria nele, mas eu nunca vi um e, portanto, não posso dizer".

Em ambas as falas ela responde adequadamente, considerando os critérios definidos por Luria, embora o tema central de sua fala não seja a intenção de responder, mas sim de afirmar uma tese, que inferimos ser: "é preciso ver para dizer". A fala do entrevistador é insistentemente a mesma: solicitar de Abdurakhm uma ação - responder baseada nas palavras das premissas - que ela, de forma complexa, recusa e justifica, afirmando sua tese. A nosso ver, em sua justificativa, há indícios que sugerem que sua "incapacidade" de responder está mais ligada a fatores culturais do que cognitivos (se entendermos o termo no seu estrito senso).

Quando Abdurakhm diz: "Nós sempre falamos somente sobre o que já vimos; nós não falamos sobre o que não vimos", o nós parece um indicativo de uma ação partilhada pelo seu grupo, que diz de uma concepção coletiva. Esse indício nos permite refletir sobre o valor da verdade para seu grupo, que entra em confronto com a solicitação de que respondesse ao silogismo proposto baseada nas palavras do entrevistador. Nas entrevistas que citamos a seguir, vemos que o ponto de vista de Abdurakhm é compartilhado por outros sujeitos entrevistados por Luria, que sustentam coletivamente o argumento de que "pode-se falar somente do que se tenha visto".

Podemos acompanhar este movimento na entrevista de outro sujeito, Khamrak, ao qual foi apresentado o seguinte silogismo:

Algodão pode crescer somente onde é quente e seco.

Na Inglaterra é frio e úmido.

O algodão pode crescer lá?

Sujeito: Khamrak, quarenta anos, moleiro de um vilarejo isolado, analfabeto.

silogismo do algodão é apresentado. 
E: $O$ algodão pode crescer onde é frio e úmido?

S: Não, se o solo for úmido e frio, ele não pode.

E: Bem, na Inglaterra é úmido e frio. $\bigcirc$ algodão crescerá ali?

A mulher do sujeito fala espontaneamente: É frio aqui também.

E: Mas lá é sempre úmido e frio. $\bigcirc$ algodão crescerá?

S: Eu, eu não... eu não sei como é o tempo lá!

(Os dados da premissa menor são ignorados; recorre à experiência pessoal).

$\mathrm{E}: \mathrm{O}$ algodão não pode crescer onde é frio, e é frio na Inglaterra. $\mathrm{O}$ algodão cresce ou não lá?

S: Eu não sei... se é frio, ele não cresce, ao passo que se for quente ele cresce. Das suas palavras, eu deveria dizer que o algodão não cresce lá. Mas eu teria de saber como é a primavera lá, que tipo de noites eles têm.

(Possibilidade de inferência a partir "das suas palavras", mas referência à falta de experiência pessoal). (Luria, 1990, p. 148-9)

Observamos que, em seu primeiro enunciado, há a resposta para o silogismo: “Não, se o solo for úmido e frio, ele não pode." Mas o entrevistador continua insistindo, talvez porque a resposta contém uma condicional [se], inadmissível, já que a premissa menor, na sua percepção (que é baseada na lógica formal), tem estatuto de verdade, que Khamrak parece não incorporar, substituindo "a Inglaterra" por "o solo".

Mais adiante, Khamrak vai inclusive reconhecer a intenção do entrevistador, expressando-a, porém fazendo uso do emprego argumentativo da conjunção [mas] e do verbo [deveria], subordinando essa posição - a do entrevistador - à que ele considera primordial - a sua própria, guiada pelo seu argumento central: "Das suas palavras, eu deveria dizer que o algodão não cresce lá. Mas eu teria de saber como é a primavera lá, que tipo de noites eles têm".

Khamrak reafirma seu argumento, admitindo ter consciência da natureza da tarefa solicitada, mas fazendo prevalecer sua perspectiva: posso falar daquilo que tenha visto/ que saiba. Inclusive inclui na resposta dados significativos, relacionados à sua prática concreta de trabalho na terra.

Em suas avaliações pontuais - entre parênteses, ao final dos enunciados dos sujeitos - Luria descreve a referência dos sujeitos à experiência pessoal - diríamos coletiva - como uma limitação ao pensamento abstrato, como uma forma de pensamento que ele caracteriza como "gráfico-funcional", em oposição ao pensamento "teóricoverbal".

Pelas palavras dos entrevistados, também podemos entender sua concepção: falar(usar a palavra para expressar uma afirmação verdadeira) está vinculado a ter visto (saber legitimado pela experiência). 
Lembrando que tanto Abdurakhm quanto Khamrak são pessoas que viveram toda a sua vida num vilarejo isolado de Kashgar, o qual se caracterizava pela cultura oral, podemos pensar um pouco sobre o papel das palavras nessa cultura. Como forma básica de relacionamento interpessoal e de conhecimento, a palavra tem peso de responsabilidade, e é critério de verdade. A falsa palavra, nesse contexto, corresponde a falta grave. Talvez por isso a dificuldade de Abdurakhm e seus companheiros de formular um juízo que, a seu ver, parece "descalçado", porque baseado unicamente nas palavras de um estranho.

Refletindo sobre esses primeiros indícios, arriscaríamos dizer que a experiência pessoal e coletiva é critério de validação para esse grupo, baseado na tradição oral da palavra. Acreditamos que, da tese central dos sujeitos, podemos compreender algumas concepções da sua cultura, que vêm interagir, e se confrontar, no momento da entrevista, com a perspectiva do pesquisador. As três concepções que os indícios nos apontam são relativas ao valor da palavra, ao conceito de verdadee ao papel da experiência, concepções essas que estão intimamente relacionadas e, juntamente com outras a que faremos referência mais adiante, organizam o rea/e são constituintes da cosmovisão e das lógicas relativas a essa organização.

Como é possível "tomar" concretamente a palavra, entendida como "arena das contradições", fenômeno objetivo que, refletindo a dinâmica de sua constituição, nos permite compreender, dentre outras coisas, os conflitos e confrontos ideológicos, as formas de orientar-se para a realidade, e a própria posição sócio-histórica dos sujeitos enunciadores, os modos de agir pela/na palavra? Bakhtin ( 1992) nos dá pistas dos /ugares em que isto seria possível: ( I ) na tentativa de monovalência do signo pelo dominante e (2) na sua subversão.

Por que a opção de tomar a palavra, como centro no qual podemos compreender a complexidade dos enunciados dos sujeitos de Luria? Em primeiro lugar, porque a palavra, como fenômeno objetivo, permite-nos ver reflexivamente seus processos de mediação e criação, ao mesmo tempo que os "modos de uso" (Certeau, 1994) dos sujeitos enunciadores, modos que refletem lógicas diversas. Sendo o material de nossa "leitura" entrevistas que descrevem "diálogos", temos a possibilidade de buscar indícios das perspectivas de ambos os sujeitos - pesquisador e entrevistados - em seus enunciados.

Mais interessante é que, já no início da releitura, encontramos conflitos entre formas de perceber a palavra - no dizere no uso do dizer. Ou seja, mais que tratar da palavra, vamos tratar de concepções múltiplas sobre a palavra, e acreditamos que, com base nesse centro temático, os demais indícios possam fazer sentido, na perspectiva cuja construção iniciamos. 


\section{MONOVALÊNCIA DA PALAVRA}

- Faze o que te mando - disse Dom Quixote -, que nem todas as coisas deste castelo hão de ser guiadas por encantamento.

Sancho foi buscar a bacia, e assim que Dom Quixote a viu, tomou-a nas mãos e disse: - Vejam Vossas Mercês com que cara pode dizer este escudeiro que isto é bacia e não o elmo que eu disse, e juro, pela ordem da cavalaria que professo, que foi este elmo que eu conquistei, sem lhe ter tirado ou acrescentado coisa alguma. (...)

- Que lhes parece a Vossas Mercês, senhores - disse o barbeiro -, o que afirmam estes homens de prol, que ainda porfiam que esta bacia é elmo?

- E a quem o contrário disser - acudiu Dom Quixote - Ihe farei eu conhecer que mente se for cavaleiro, e se for escudeiro, que mente e remente mil vezes. (Cervantes Saavedra, 1978, p. 268)

No capítulo “Dedução e Inferência”, Luria( 1990 , p. I 35) busca investigar a natureza do pensamento lógico-discursivo, analisando a ocorrência, ou não, de inferências silogísticas.

Em relação às entrevistas deste capítulo, ele avalia que os sujeitos participantes da pesquisa fazem julgamentos sobre fatos relacionados com a experiência, revelando uma "inteligência bastante mundana" (Luria, I990, p. I 53). Quando porém, Ihes é solicitado um sistema de pensamento teórico, que faz uso de inferências silogísticas, fatores limitam sua capacidade para o "pensamento lógico-verbal". Entre eles, destacam-se a não aceitação da universalidade das premissas, a falta de confiança na premissa inicial e a desintegração do silogismo em três proposições independentes, sem lógica unitária. Na avaliação do pesquisador, as relações lógicas são negadas, em favor das experiências imediatas.

Como então podemos, com base nas avaliações que Luria vai pontuando no decorrer das transcrições das entrevistas e das suas avaliações conclusivas ao fim dos capítulos, tentar entender a concepção de palavra, tomada como pressuposto e orientação teórica da pesquisa e do pesquisador? Pensamos que um caminho para essa compreensão é buscar indícios reveladores, nas falas dos entrevistadores, nos diálogos que travam com os entrevistados, nas réplicas que elaboram e nas avaliações de Luria a respeito das falas dos sujeitos entrevistados.

Nosso argumento é que, em Luria, há uma crença implícita de que a perspectiva lógico-formal, entendida como processo de dedução por inferência silogística, seria a forma do pensamento humano desenvolvido. Nessa perspectiva, o pensamento lógicoverbal é aquele no qual, a partir de premissas gerais e espećficas, é possível inferir-se uma conclusão única e universalmente válida, decorrente da relação entre as premissas. O que 
são as premissas? São duas afirmaç̧ões, enunciados cuja veracidade não cumpre questionar, que devem ser relacionadas num raciocínio desencadeador de uma terceira, conclusiva, igualmente não questionável. Essa crença é representativa de uma verdade, dentro de uma comunidade que compartilha das regras de sua produção.

Para Luria, quando ele diz as palavras implicam, o que está em jogo é essa relação silogística. A palavra, nessa maneira de entender, é veiculadora de uma relação lógica, cuja forma é convencionada na comunidade estrita da ciência que a considera verdadeira e universal, como parâmetro de uma forma de pensamento "mais desenvolvido", porque distanciador, porque abstrato. O pensamento lógico-verbal, portanto, se afastaria do sentido das palavras, nelas considerando apenas o desencadeamento silogístico das premissas. A palavra é esvaziada dos seus laços com o contexto de sua produção, com as concepções múltiplas que a constituem sócio-historicamente - plurivalência do signo -, e com as perspectivas dos sujeitos enunciadores. É signo estático, se paralisado dentro de um sistema lógico, cujas relações só têm uma conclusão "óbvia" que deve ser aceita como verdadeira. É signo monovalente, como diz Bakhtin (1992, p.36-8), apropriado por uma categoria de pessoas e utilizado para refrataros sujeitos que não se reconhecem nesse sistema restrito.

Possivelmente por este motivo, apesar dos sujeitos da pesquisa, no nosso entendimento, apresentarem em seus enunciados as respostas esperadas dos silogismos, estas não são reconhecidas como legítimas, pois subvertem a lógica imposta. Tal subversão se dá porque trazem, para o plano do esperado, do monológico, o dialogismo e as próprias relações que os sujeitos estabelecem, com base em seu universo social e histórico, e também sua prática concreta de sujeitos, agindo no mundo segundo sua cultura.

Assim parece ser, no fragmento da entrevista de Abdurakhm:

E: Mas o que as minhas palavras implicam? O silogismo é repetido.

S: Bem, é assim: nosso czar não é como o seu e o seu não é como o nosso. Suas palavras somente podem ser respondidas por alguém que esteve lá, e se uma pessoa não esteve lá ela não pode dizer nada baseada em suas palavras.

E: Mas com base nas minhas palavras - no norte, onde há sempre neve, os ursos são brancos - você pode entender que tipo de ursos existem em Novaya Zemlya?

A insistência do entrevistador desconsidera a justificativa da entrevistada, pois possivelmente o que ele busca é a conclusão "brancos", que a nosso ver, ela já havia enunciado, em: "S: Eu não sei; eu já vi um urso negro, eu nunca vi outros... Cada localidade tem seus próprios animais: se é branco, eles serão brancos, se for amarelo, eles serão amarelos". 
O que parece é que só há uma possível palavra aceita para o pesquisador. Quando o sujeito apresenta outra elaboração enunciativa que não a esperada, sua avaliação se faz com a utilização de palavras como "falha",

O seguinte silogismo é apresentado: No Norte, onde há neve, todos os ursos são brancos. Novaya Zemlya fica no norte e lá sempre neva. De que cor são os ursos lá?

S: Há diferentes tipos de ursos.

("Falha" em inferir a partir do silogismo)

O silogismo é repetido.

à qual o entrevistador generosamente oferece uma segunda chance, repetindo as palavras que ele crê deterem implicitamente a verdade da resposta esperada.

Os sujeitos da pesquisa demonstram inclusive compreender a intenção do pesquisador, mas não se submetem à sua lógica, como já observamos na entrevista de Khamrak. Mesmo Khamrak respondendo de acordo com os critérios de validade estabelecidos pelo pesquisador, a "experiência pessoal" é fator que "atrapalha" a linearidade do pensamento, portanto a entrevista não está incluída entre as que Luria considera satisfatórias.

Mesma situação observamos na entrevista de Rustam:

E: Mas você pode responder à pergunta baseando-se nas minhas palavras?

S: Uma pessoa que viajou muito e esteve em países frios e viu uma porção de coisas saberia responder: ela saberia de que cor são os ursos.

(Fracasso ao inferir com base nas premissas do silogismo e apelo à necessidade da experiência pessoal para poder responder à questão). (Luria, 1990, p. I47)

Na seqüência desta entrevista, observamos um diálogo entre concepções diversas do termo "disse": para o pesquisador, a concepção é de ter "dito" as premissas; para Rustam, "dizer" implica outras questões, relacionadas ao valor da experiência para seu grupo cultural: a pessoa que fala fornece um contexto para a enunciação, que se torna critério de verdade, pelo pressuposto que, como já vimos anteriormente em outras entrevistas, pode-se dizer daquilo que se saiba/que se tenha visto:

E: Bem, no norte, na Sibéria, há sempre neve. Eu Ihe disse que onde há neve os ursos são brancos. Que tipo de ursos há no norte, na Sibéria?

S: Eu nunca fui à Sibéria. Tadzkibai-aka, que morreu no ano passado, esteve lá. Ele disse que havia ursos brancos, mas ele não disse de que tipo. (grifos nossos, idem, p. 147)

Mais uma vez, a palavra válida é única e universal (monovalente) na perspectiva do enunciador, tanto que ele não reconhece a resposta que Rustam contextualiza, para responder: "Ele disse que havia ursos brancos, mas ele não disse de que tipo". 
Na totalidade das entrevistas do capítulo sobre o processo de dedução baseada nos silogismos, a concepção de palavra que guiou o olhar de Luria parece ser a da palavra somente válida se desencadeada a partir das suas, expressas nas premissas. Congelando as múltiplas possibilidades de respostas outras, têm-se como resultado a refração do sujeito na palavra. A palavra monovalente, desconsiderando as interações outras que os sujeitos realizavam a partir dela e nela, os exclui, por conseguinte, da possibilidade de participarem dos processos lógicos que envolvem o ato de dizer, na concepção de Luria. As respostas dos sujeitos só podem ser avaliadas como "falta", em relação ao parâmetro estabelecido pelo pesquisador.

Mas o confronto de concepções sobre a palavrafica mais evidente nas entrevistas do capítulo "Generalização e Abstração" (Luria, 1990, p.65).

Nesse capítulo, Luria busca estudar a ocorrência de categorizações abstratas, utilizando atividades de classificação de objetos, o que envolveria, na sua perspectiva, processos cognitivos como "pensamento verbal e lógico complexo, que explora o potencial da linguagem em formular abstrações e generalizações para selecionar atributos e subordinar objetos a uma categoria geral". A avaliação das entrevistas realizadas é a de que as tarefas teóricas propostas são substituídas, nas respostas, por uma reprodução das "relações práticas entre os objetos". Os sujeitos não utilizavam a forma de agrupamento baseada no "pensamento categorial", que consiste em "comparar e agrupar objetos em termos abstratos e subordiná-los a categorias especíicas". Ao contrário, realizavam agrupamentos segundo os papéis dos objetos numa situação prática, ou seja, "reproduziam procedimentos retirados de sua experiência diária de trabalho" (Luria, 1990, p.73), por um princípio de "funcionar junto". Luria denominou este tipo de pensamento como "situacional", ou seja, preso ao concreto.

Em "O Processo de Dedução", a palavra era verdadeira porque decorrente da relação lógica silogística, e somente nesse sentido poderia ser aceita. Neste capítulo, a palavra é monovalente; e, ainda, tem sentido literal, como categoria. As palavras convencionadas para designar categorias de objetos, no sentido que é dado por uma língua dominante, são confrontadas nas entrevistas por sentidos múltiplos, intimamente relacionados com o universo sócio-histórico dos sujeitos do Uzbequistão, e que, por subverterem o sentido literal que Luria crê ser o único válido, são considerados como produtos de um pensamento não abstrato, preso à situação, portanto mais uma vez como "falta".

É apresentada aos sujeitos uma série de objetos - machado, serra, tora, martelosendo três deles pertencentes a uma "categoria" que poderia ser expressa por uma palavra - ferramentas - e lhes é solicitado que retirem da série o objeto que não pertence à categoria, que não é seme/hanteaos outros três - as "ferramentas". 
As respostas seguem um padrão: os sujeitos relacionam os objetos entre si, e dizem que todos são necessários, na relação que estabelecem. O pesquisador "força" a relação lógica categorial, desconsiderando a lógica própria que os sujeitos demonstram e constroem na situação de entrevista. Mas disso trataremos mais adiante. Importante aqui é entender qual é a concepção de palavra que nos revela Luria.

Na entrevista de Sher, ao ter o sujeito se negado a retirar da série qualquer um dos objetos, o entrevistador interfere:

E: Mas uma pessoa me disse que a tora não pertencia a este grupo.

S: Por que diria isso? Se nós dissermos que a tora não é como as outras coisas e a colocarmos de lado, estaremos cometendo um erro. Todas essas coisas são necessárias para a tora.

(Considera a idéia de utilidade mais importante que a de semelhança). (Luria, 1990, p.79)

A "idéia de utilidade" é o que Luria consegue compreender da fala de Sher, contrapondo à de semelhança, seu próprio critério de agrupamento. Podemos ter um melhor entendimento dessa "crença" de Luria no seguinte fragmento da entrevista de Sher em que, apesar deste questionar admiravelmente a proposta de utilizar uma palavra para expressar uma série de objetos, sua resposta é desconsiderada pelo entrevistador, que "força" seu ponto de vista, repetindo a proposta, a despeito da negativa justificada:

E: Olhe, você pode usar uma palavra - ferramentas - para esses três, mas não para a tora.

S: Que sentido faz usar uma palavra para todos eles se não vão trabalhar juntos?

(Rejeita o uso do termo genérico).

E: Que palavra você poderia usar para essas coisas?

S: As palavras que as pessoas usam : serra, machadinha. Você não pode usar uma palavra para todos! (idem, p.79-80)

Nesta outra entrevista, com três sujeitos, $\operatorname{Kar}$ (SI), Yarb (S2) e Mad (S3), a insistência é a mesma: utilizar uma palavra para representar objetos pertencentes a uma "categoria". Os sujeitos, apesar de estimulados a responder de acordo com os critérios do pesquisador, e mostrarem uma compreensão a respeito do termo genérico, não resolvem a tarefa, porque não absorvem a lógica proposta em detrimento da sua própria.

E: Mas você pode usar uma palavra - ferramentas - para elas, não pode?

SI, S2, S3: Sim, claro.

E: E você não pode usar essa palavra para tora?

S: Não. 
E: Isso significa que essas três têm alguma semelhança?

S: Sim.

E: E se eu pedir para você pegar as três coisas que você pode chamar por uma só palavra, quais você pegaria?

SI : Eu não entendo.

S2: As quatro.

S3: Se não pegarmos a tora, não teremos necessidade das outras três.

(Substitui o termo genérico por argumentos sobre funções práticas). (Idem, p. 85)

Nos seguintes fragmentos das entrevistas dos três sujeitos, observamos uma análise, por parte de Luria, do emprego da palavra em questão - ferramenta - por parte dos sujeitos:

E: Mas eu não posso chamar madeira de ferramenta!

S3: Pode sim - você pode fazer rabiças com ela.

(..)

E: Mas você pode realmente dizer que a madeira é uma ferramenta?

S2: Ela é! Os postes são feitos com ela, as rabiças... Chamamos de "ferramentas" todas as coisas de que temos necessidade.

(Utilizam a palavra "ferramenta" de maneira determinada pelo princípio da necessidade). (Idem, p. 125)

Observe que Yarb não só justifica logicamente sua opção de incluir a madeirano grupo de ferramentas (trabalhando na perspectiva lógica do pesquisador), como é capaz de conceituar a palavra categorial, descrevendo como seu grupo cultural - nós - concebe o significado da palavra. Luria não percebe o processo de categorização realizado segundo outros critérios, porque a sua interpretação - "maneira determinada pelo princípio da necessidade" - é um dizer que silencia a lógica dos sujeitos, subordinando-a à sua própria. Podemos dizer que, para Luria, o significado literal da palavra "ferramenta" relaciona-se unicamente com a sua função como "categoria", dentro de uma única possível significação categorial - digamos, instrumentos de metal que servem para o trabalho. É a monovalência da palavra, que, de novo, refrata as múltiplas maneiras possíveis da relação ser-signo, entendendo ambos como sócio-historicamente constituídos numa unidade dialética produtora.

Interessante paradoxo podemos ver entre essas concepções e o próprio objetivo do trabalho de pesquisa de Luria: a sua perspectiva é sócio-histórica, e tem como um de seus pressupostos fundamentais justamente o entendimento de que o desenvolvimento dos processos mentais tem sua origem nas relações entre os sujeitos e suas culturas. Se a cultura é produzida historicamente pela ação dos seres humanos no mundo, e se a cogniçãoé relativa a essas ações e relações, relegar às "experiências imediatas" 
o papel de algo que limita é, em si, contraditório com a perspectiva assumida - sóciohistórica -, a menos que outros fatores entrem em jogo nessa avaliação. Acreditamos que um deles seja o pressuposto de que os critérios aceitos para se determinar uma cultura como legítima estejam predeterminados, pressupostos, preconceituados, e guiem o olhar do pesquisador na busca das interpretações das falas dos sujeitos. A hipótese é de que esses critérios estão intimamente relacionados com os da lógica formal. Acreditamos que essa forma específica de raciocínio, absolutizada como modelo de racionalidade, é utilizada como parâmetro nas avaliações de Luria, obnubilando seu olhar para a complexidade das respostas que os sujeitos Ihe ofereceram.

A monovalência da palavra é um traço marcadamente presente nas falas e escritas de Luria. A palavra é capturada e apresentada aos sujeitos no âmbito do entendimento da lógica formal, excluindo formas culturalmente constituídas e constitutivas de participação sócio-histórica dos sujeitos nas formas de dizer e de pensar. Dupla exclusão, que elimina a possibilidade de serem legítimas as formas de ser que sustentam e são sustentadas por elas. O sentido literal da palavra, como diz Certeau (1994), reduz as outras formas possíveis a serem heréticas - fora do sentido - ou destituídas de sentido verdadeiro "entregues ao ouvido": "Deste ponto de vista, o sentido 'literal' é o sinal e o efeito de um poder social, o de uma elite."

O sentido monovalente e literal das palavras foi como que "imposto" aos sujeitos, ou como decorrência lógica da relação entre premissas esvaziadas de sentido, ou como "categorias" com sentido pré-convencionado. Ato de silenciamento das alternativas diversas, porém igualmente legítimas.

Falamos de crenças, daquelas que trazemos no olharpara o momento do encontro com o outro. A crença de Luria é na possibilidade da universalidade de uma forma de racionalidade, crença esta na qual ele investe e da qual reveste os sujeitos cujo pensamento estuda. Há um pressuposto evolutivo na transição que descreve, do concreto para o abstrato; em seu trabalho Luria afirma que essa "passagem" está relacionada a uma mudança nos tipos de atividades concretas com as quais os sujeitos interagem, ou seja, a base material de sua existência ou os modos de produção. A pesquisa justifica-se, portanto, ao comparar resultados de entrevistas de sujeitos não alfabetizados de vilarejos isolados com sujeitos em processo de alfabetização e trabalhadores de fazendas coletivas reestruturadas pela revolução soviética. O pesquisador encontra-se num lugar intermediário: o contexto da produção de sua teoria é o da crença na civilidade, na ciência e na razão emancipatória como instrumentos de revolução social. Nesse sentido, as formas lógicas dos sujeitos, que ele percebe mas não assimila, são o arcaico a ser superado em nome da boa-nova materialista histórica. Esses são os limites e as possibilidades de Luria. 
Vamos voltar a essas entrevistas, invertendo o prisma do olhar, para tentar pensar outras formas de crer, que possibilitem potencializar outras formas de ser racional.

\section{SUBVERSÃO}

É preciso agora olhar e ouvir as falas dos sujeitos desde outra perspectiva, e nelas buscar os indícios emergentes, que nos podem revelar outras racionalidades, intimamente relacionadas com as posições sociais e historicidade dos sujeitos e seus enunciados. Uma dimensão então a ser analisada, para a compreensão das racionalidades emergentes na situação das entrevistas de Luria, é aquela da qual só podemos perceber os indícios, revelados na interação que possibilita e onde são produzidos os enunciados. O que vamos fazer é ouvir a palavra dos sujeitos baseada nesta outra perspectiva, e formular algumas hipóteses sobre suas formas de organizar e compreender o real.

Voltemos pois, às entrevistas, e recomecemos com a tríplice concepção emergente das entrevistas de Abdurakhm, e na entrevista de Rustam - que transcreveremos na seqüência. Já vimos que o valor da palavra, para os sujeitos e seus grupos, está intimamente relacionado ao valor da experiência como condição de verdade. Mas há algo mais, sobre essa concepção do real, que as palavras revelam. Os sujeitos contrapõem à tarefa de responder ao silogismo baseando-se nas palavras do entrevistador, uma outra palavra possível, detentora da possibilidade da verdade: a palavra da experiência, sua ou de alguém que tenha vivido muito ou que tenha viajado muito:

\section{ABDURAKHM}

E: Mas com base nas minhas palavras - no norte, onde há sempre neve, os ursos são brancos - você pode entender que tipo de ursos existem em Novaya Zemlya?

$\mathrm{S}$ : Se um homem de sessenta ou oitenta anos tivesse visto um urso branco e tivesse contado sobre isso, se acreditaria nele, mas eu nunca vi um e, portanto, não posso dizer."

\section{RUSTAM}

O silogismo do urso branco é apresentado.

E: De que cor são os ursos no norte?

S: Se houvesse alguém que tivesse uma grande experiência e tivesse estado em todo lugar, ele se sairia bem em responder a pergunta.

E: Mas você pode responder à pergunta baseando-se nas minhas palavras?

S: Uma pessoa que viajou muito e esteve em países frios e viu uma porção de coisas saberia responder: ela saberia de que cor são os ursos. (Luria, 1990, p. 147) 
Se tomarmos esses enunciados de forma indissociável das condições culturais de sua produção, consideraremos que os sujeitos pertencem a grupos não alfabetizados, de vilarejos isolados, povos de tradição oral. Que sujeito é esse, que "viaja muito", ou que já "viveu muito", e cuja palavra carrega o valor da verdade para esses grupos culturais, porque estribada na experiência? Um personagem que já não faz parte de nossas culturas modernizadas. o narrador.

Benjamin (1994, p.200) nos ajuda a recuperar esse personagem: aquele que, das experiências, suas e dos outros, tece a sabedoria na "substância viva da existência". Sua figura insere-se em dois grupos de narradores anônimos: o camponês sedentário e o marinheiro comerciante; respectivamente, aquele que "viveu muito" e sabe das histórias da tradição local, e o que "viajou muito" e traz a experiência do longe. Narrando, incorporam as experiências às dos ouvintes.

Parece que essas experiências, tecidas "na substância viva da existência", ficam guardadas como "sementes", esperando a hora de serem usadas. O momento do confronto com a lógica do pesquisador é um bom momento, uma vez que este põeas suas próprias concepções sobre as concepções dos sujeitos - impõe. Vemos o movimento subversivo de trazer para o encontro com o que se põe como o outro essa reserva de sabedorias, no seguinte trecho:

\section{KAR FARF}

E: Cite todas as ferramentas usadas para produzir coisas.

SI: Nós temos um ditado: dê uma olhada nos campos e você verá ferramentas. (Luria, 1990, p. 126)

Questionado pelo pesquisador no momento em que, juntamente com outros dois sujeitos, construíam um nexo que desse conta de justificar as relações que estabeleciam entre os objetos que deveriam agrupar, Kar responde com um ditado, que expressa a concepção de sua cultura sobre o termo em questão.

Podemos tomar o conceito de provérbios de Benjamin (1994) que os considera "ruínas de antigas narrativas, nas quais a moral da história abraça um acontecimento, como a hera abraça um muro", para entender o uso que os sujeitos fazem dos dizeres. Sentidos guardados na memória coletiva da cultura, produzidos pela tessitura das experiências narradas e "acordadas" num relampejar da reminiscência. Não são obstáculos para o conhecimento verdadeiro: representam a verdade do seu conhecimento. Assim, esta arte de dizer deve ser vista como uma forma de ser racional; mais, de "abraçar" o acontecimento com a reminiscência que é sua e de seu grupo. Marca, na linguagem, reveladora da racionalidade enraizada nas relaçõe s mutuamente constitutivas entre os seres e suas culturas. 
Também as analogias se colocam como "ditos", dos quais os sujeitos lançam mão no momento do confronto com o pesquisador. As analogias devem ser compreendidas como uma forma rica e complexa de raciocínio. ${ }^{3}$ Mas também precisamos compreendê-las como uma arte de dizer, que revela tanto formas de elaboração mental como, na situação da pesquisa de Luria, uma ação que subverte a lógica proposta, pois a transgride: traz uma outra lógica, profundamente relacionada com as formas de organização do real que estes sujeitos compartilham.

E: Mas o que minhas palavras implicam? O silogismo é repetido.

S: Bem, é assim: nosso czar não é como o seu e o seu não é como o nosso. Suas palavras somente podem ser respondidas por alguém que esteve lá, e se uma pessoa não esteve lá ela não pode dizer nada baseada em suas palavras.

A negativa de Abdurakhm oferece um outro tempo de raciocínio, em que as palavras são conselheiras abertas à relação com todos e com cada um. Cabe dizer que esta "arte de dizer" é indicativa de uma grande sagacidade, de uma astúcia que não se "dobra" na relação com o entrevistador, antes se posiciona e, falando do lugardeste posicionamento, tanto resiste à "invasão" do estranho quanto se fortalece.

Podemos observar um desses momentos da construção, no nível das palavras, das concepções compartilhadas pelo grupo, na entrevista de Kar, Yarb e Mad, na qual o que parece acontecer é uma elaboração polifônica das enunciações. O que parece é que, para tornar compreensível seus pontos de vista para o entrevistador, os sujeitos vão tornando palavras concepções que, por serem compartilhadas, não necessitavam da palavra anteriormente:

Os participantes eram Kar Farf, 25 anos ( I); Yarb Mamar, 32 anos (2); Mad Suleim, 26 anos (3). Os três sujeitos, camponeses analfabetos da aldeia de Palman ou nunca haviam estado numa cidade ou raramente haviam visitado uma. A seguinte série lhes foi apresentada: martelo - serra - tora - machadinha.

E: Se você tivesse de colocar essas coisas em algum tipo de ordem, você poderia tirar a tora do grupo?

SI: Não, se você se livrar da tora, para que vão servir as outras coisas?

E: Mas essas três coisas são ferramentas, certo?

SI: Sim, são ferramentas.

E: E a tora?

3. Em Tratado da argumentação: a nova retórica, Perelman e Olbrechts-Tyteca (1996) apresentam-nos as analogias como formas de raciocínio complexas, que buscam aproximar estruturas não conhecidas de outras familiares aos sujeitos. 
S1, S2, S3: Ela também faz parte. Você pode fazer todo tipo de coisa com ela maçanetas, portas, até mesmo o cabo das ferramentas é feito de madeira!

S2: Nós dizemos que é uma ferramenta porque tudo é feito de madeira, então ela combina com as outras coisas.

E: Mesmo assim, essas três coisas não são parecidas de alguma maneira?

S2: Não, o que está faltando aqui é um homem, um trabalhador. Sem ele, não há nada parecido entre essas três coisas.

S3: Você tem de deixar a madeira aquil Não há nada parecido entre essas três coisas a menos que a tora esteja aqui. Se você deixar a tora, elas são todas necessárias, mas, se você não deixar, para que elas servem?

E: E se eu pedir para você pegar as três coisas que você pode chamar por uma só palavra, quais você pegaria?

S। : Eu não entendo.

S2: As quatro.

S3: Se não pegarmos a tora, não teremos nenhuma necessidade das outras três.

E: Mas uma pessoa me disse que uma tora não é uma ferramenta. Afinal, ela não pode cortar, não pode serrar.

S3: Não, quem lhe disse isso deve ser louco. Para fazer uma ferramenta você precisa de uma tora. Parte da tora é usada para fazer o cabo de uma serra, de modo que a força de uma tora também é usada no corte. A tora não pode cortar sozinha, mas junto com a machadinha ela pode. (Luria, 1990, p. 84-6)

E: Mas eu não posso chamar madeira de ferramenta!

S3: Pode sim - você pode fazer rabiças com ela.

E: Mas você pode realmente dizer que madeira é uma ferramenta?

S2: Ela é! Os postes são feitos com ela, as rabiças... Chamamos de "ferramentas" todas as coisas de que temos necessidade.

E: Cite todas as ferramentas que você puder.

S3: Um machado, uma mosque (charrete com molas) e também a árvore onde amarramos um cavalo, se não houver um poste por perto. Olhe, se não tivéssemos esta prancha aqui, não teríamos condições de segurar a água nesta vala de irrigação. Por isso, ela também é uma ferramenta, como também é a madeira com que se faz um quadro-negro.

E: Cite todas as ferramentas usadas para produzir coisas.

SI: Nós temos um ditado: dê uma olhada nos campos e você verá ferramentas. (Idem, p. I25-6) 
Já no início da entrevista, Kar vai revelar uma outra forma de organizar os objetos que o pesquisador the oferece: de forma a integraros objetos entre si, numa perspectiva que assinalamos como relacionaft - os objetos são "semelhantes" a partir da/na relação que se estabelece entre eles, relação esta ligada às práticas da sua cultura. Interferência do sujeito organizador na realidade observada. Quando eles dizem: "Não, se você se livrar da tora, para que vão servir as outras coisas?", os sujeitos demonstram a forma de relacionar os objetos, mas o entrevistador considera que não foi estabelecida uma "ordem" - no sentido estrito de uma forma de agrupamento que a lógica formal determina.

Quando Luria fornece o nome da categoria em que os objetos deveriam ser agrupados: "E: Mas essas três coisas são ferramentas, certo?", os sujeitos, que aparentemente "incorporam" a categoria, na realidade se utilizam da palavra do entrevistador para cunhar nela seu próprio ponto de vista. Quando, na fala, elaboram que "a madeira é ferramenta porque faz coisas", e porque até mesmo faz as ferramentas que a trabalham, Yarb constrói um conceito de ferramenta que justifica a relação na qual eles crêem: "S2: Nós dizemos que é uma ferramenta porque tudo é feito de madeira, então ela combina com as outras coisas."

Aqui já se observa a penetração do raciocínio categórico solicitado pelo pesquisador, mas também vemos que um conceito foi construído, de modo a justificar e a amparar o seu ponto de vista, legitimando-o diante do entrevistador.

Ainsistência do entrevistador vai gerar um raciocínio de inclusão, que fortalece a construção anterior: "S2: Não, o que está faltando aqui é um homem, um trabalhador. Sem ele não há nada parecido entre essas três coisas."

Podemos tentar elaborar o tipo de relação estabelecida pelos sujeitos da seguinte forma: os objetos se assemelham na relação que mantém entre si. Serra, machadinha e martelo são instrumentos que só fazem sentido na sua relação com a tora. Isso fica mais claro quando da inclusão do homemno grupo. Luria considera essa forma de agrupamento "situacional", ou presa à situação. Podemos dizer que o pensamento que os sujeitos revelam é lógico: existe uma relação de semelhança, tanto que outros "objetos" podem ser inseridos no grupo, mas é uma semelhança que existe na relação que se trava entre eles. Consideramos que é mais que um agrupamento temático. Diz respeito a uma

4. O termo relaciona/vem sendo utilizado, por autores como Newman, Griffin e Cole ( $199 \mid$ ), para designar uma determinada forma de representar elementos de um conjunto, sob a forma de relatos, configurando um tema coherente, em contraste com o campo de representações chamado taxonômico ou categorial. Nossa própria denominação, nesta releitura das entrevistas de Luria, se diferencia deste sentido temático-relacional. Relacional, a nosso ver, refere-se a uma organização em que cada elemento analisado tem seu sentido vinculado à relação que se estabelece entre ele e os demais, incluindo a própria ação humana e intersubjetiva no interior de uma cultura. 
certa prática social, não a prática concreta do trabalho, simplesmente, mas uma certa forma de relacionar-se com o mundo: as coisas fazem sentido na relação, porque sua perspectiva é interativa.

Entendemos que melhor seria chamarmos essa forma de "agrupamento" de organização, uma vez que o princípio do processo não seria a comparação e a separação de atributos, mas sim a relação estabelecida entre os elementos. Essa organização não é simplesmente situacional como analisa Luria, mas sim relacional, como já interpretamos, e não se pode dizer que denota uma falta de desenvolvimento; antes devemos entendêla como relações desenvolvidas, num sistema lógico. Um indício dessa afirmativa pode ser encontrado no seguinte enunciado de Mad:

S3: Não, quem lhe disse isso deve ser louco. Para fazer uma ferramenta você precisa de uma tora. Parte da tora é usada para fazer o cabo de uma serra, de modo que a força de uma tora também é usada no corte. A tora não pode cortar sozinha, mas junto com a machadinha ela pode.

Quando ele identifica a proposição feita pelo pesquisador como obra de um louco, isso significa, a nosso ver, que ela é incoerente com a sua própria organização lógica, que ele justifica, relacionando entre si os objetos com base nas referências de organização do real que a sua inserção e vivência na cultura possibilitam.

No final da entrevista dos sujeitos vemos como o significado construído a respeito da palavra "ferramenta" foi tecido a quatro vozes, e afirmado, até culminar no "ditado", dizer mais genérico, que amplia o significado da palavra para incluir o ponto de vista de todo o seu grupo cultural, social e histórico. $\bigcirc$ entrevistador, fixado na sua perspectiva, só faz repetir o mesmo questionamento, que desqualifica insistentemente o ponto de vista dos sujeitos.

Yarb realiza até mesmo uma tarefa complexa: elabora uma definição para a palavra "ferramenta": "Chamamos de 'ferramentas' todas as coisas de que temos necessidade", o que já seria suficiente para ao menos ser identificado um conflito entre as significações diversas da palavra categorial. Mas a insistência do entrevistador é denotativa de sua não compreensão dos processos racionais revelados na fala dos sujeitos entrevistados.

O que compreendemos é que as formas diversas de organização - que chamamos relacionais - são também lógicas, intimamente relacionadas com as perspectivas sócio-históricas dos sujeitos nas culturas e, ainda, foram coletivamente construídas na entrevista. A partir do momento que são verbalmente elaboradas pelos sujeitos, eles passam a utilizar teoricamente o sistema estabelecido, afirmando-o e sendo capazes de inserir nele outros elementos, como na resposta de Mad, elaborada considerando-se a conceituação de Yarb: 
E: Cite todas as ferramentas que você puder.

S3: Um machado, uma mosque (...) e também a árvore onde amarramos um cavalo (...). Olhe, se não tivéssemos esta prancha aqui, não teríamos condições de segurar a água nesta vala de irrigação. Por isso, ela também é uma ferramenta (...).

Os enunciados dos sujeitos nos revelam racionalidades. Isso parece apontar no sentido do entendimento de que formas culturais diversas podem levar a formas diversas de organização do real. Certo é que, a partir dessa definição, não se é possível aceitar que haja umaforma racional absoluta.

Cremos que o que podemos estabelecer aqui são algumas linhas gerais, a partir dos indícios encontrados, que nos ajudem a entender essas racionalidades reveladas. Os sujeitos de Luria compartilham de um determinado lugar sócio-histórico; são um povo de tradição oral, pessoas que vivem e trabalham juntas, que têm o coletivo como referência. Para eles, uma palavra pode ser tomada como expressão da verdade, desde que tenha relação com a experiência. Não se trata de estar arraigado num fazer nãoreflexivo; trata-se de um outro critério de verdade - a sabedoria - tecida no entrecruzamento espaço-temporal das experiências narradas. Mas a palavra viva, nesse sistema dinâmico e sócio-histórico, é usada - de modo astuto - para subverter uma lógica estranha, a do pesquisador.

Talvez possamos dar mais um passo em nossa construção teórica, e dizer que existe um princípio fundador dos processos, que encontramos nas diversas falas: o paradigma revelado pelos sujeitos é relacional- os seres, os objetos, o mundo, fazem sentido na interação cultural que se estabelece entre eles e os seres humanos. Dessa forma, a palavra, como expressão do real, traz a marca de uma realidade construída por/ com os seres humanos. Por isso é indissociável das relações que os seres humanos travam com o mundo. Como diz Sher: "Que sentido faz usar uma palavra para todos eles se não vão trabalhar juntos?"

Os enunciados dos sujeitos entrevistados por Luria revelam-nos uma profunda coerência entre seus modos de fazer (ações compartilhadas), modos de ser (coletividade), modos de dizer (relacionando experiências, usando astutamente a palavra construída culturalmente) e modos de pensar (de forma relacional).

As suas formas de organização do real fazem-nos, em última análise, refletir sobre nossa própria incapacidade de sermos relacionais, presos que estamos em nosso paradigma dualista e individualista. Seus modos de fazer, dizer, pensar, ser nos lembram daquilo que esquecemos: somos parte interativa e indissociável da historicidade da cultura e da natureza. 


\section{ALGUMAS CONCLUSÕES}

A primeira análise possível é geral. Lança um olhar para a totalidade das entrevistas e diz respeito à metodologia de pesquisa utilizada por Luria e sua equipe, aos pressupostos teóricos e às concepções de lógica emergentes no trabalho citado. O pesquisador estava em campo, diante dos sujeitos da pesquisa, com um objetivo claro e delimitado: verificar a natureza social e histórica dos processos mentais, utilizando os critérios da lógica formal. As regras às quais os sujeitos foram submetidos são do domínio estrito do método do pesquisador, e dizem respeito a uma concepção que, no limite, acredita na universalidade de umaúnica forma possível de ser racional: aquilo que "escapa" à regra é classificado como não, como déficit, como falta. Na própria concepção de falta está implícito o parâmetro; nesse caso, os critérios da lógica formal. A ordem científica, na perspectiva de Luria, marca o diferentenuma escala de "desenvolvimento", como o que falta ao próprio. A diversidade é enclausurada num sistema gradual (do simples ao complexo), e unicamente desta forma pode ser percebida.

Retomando as avaliações de Luria, encontramos um paradoxo: encontramos nos enunciados dos sujeitos as respostas solicitadas às tarefas, mas o pesquisador não considera as respostas como corretas, pelos seus critérios. Como podemos tentar entender esse fato? O raciocínio, para os lógicos, é um processo sintático, no qual as regras formais aplicam-se às premissas, sem que seja necessário considerar seus significados. Em nossa releitura, encontramos indícios que parecem apontar para uma compreensão de que, para Luria e sua equipe, o que estava sendo negociado era a aplicação das regras formais às premissas propostas.

Por isso a resposta dos sujeitos entrevistados, mesmo que correta e logicamente justificada, é sistematicamente desconsiderada: Luria não estava preocupado com o conteúdo da resposta, mas sim com a sua forma de apresentação, que deveria ser derivada diretamente da relação entre as premissas. Seria correto dizer que o que estava em jogo, para o entrevistador, não era o conteúdo do discurso, mas o próprio discurso, ou seja, como diz Rojo (1 997, p. I05), o "léxico adequado a um certo gênero de discurso", no caso, uma estrutura lógico-formal. Dentro dessa perspectiva, quanto mais isomórfica se mostravam as respostas dos sujeitos, mais imediatamente eram aceitas como legítimas, como neste exemplo, no qual Luria considera que o sujeito realizou com efeito a inferência silogística:

Sujeito: Gasur Akbar, vinte e seis anos, viveu dois anos em uma fazenda coletiva, semianalfabeto.

O silogismo do algodão é apresentado.

E: Que você acha, o algodão cresce na Inglaterra? 
S: Não, se é úmido e frio, ele não crescerá.

O silogismo do urso branco é apresentado.

S: Você disse que lá é frio e neva, portanto os ursos lá são brancos. (Luria, 1990, p. 152)

Isso remete a várias questões, que gostaríamos de discutir brevemente. Primeiramente, o tipo de pensamento que a lógica formal vem privilegiar no estudo do pensamento humano é constituído por uma linearidade que não é a característica do discurso intersubjetivo cotidiano.

Tfouni ( 1988), uma das pioneiras na análise do pensamento adulto, utilizando silogismos ${ }^{5}$ analisa as respostas de seus sujeitos - produção de sincretismos nas justificativas - como produtos de uma situação dialógica, em que esses procuravam articular os conteúdos das premissas com a sua experiência pessoal. Propõe, com base no resultado, uma mudança na metodologia do estudo da cognição, substituindo-se a consideração do "produto" do pensamento - a resposta ao silogismo - pela abordagem do sujeito como sujeito do discurso, numa situação dialógica. Apesar de a autora apontar para a necessidade do entendimento da não separação da formae do conteúdo dos enunciados dos sujeitos, na situação discursiva, gostaríamos de acrescentar que também esses enunciados não podem ser entendidos separadamente das suas referências culturais.

Alguns estudos de psicologia (Roberge, Paulus; Wason, Johnson-Laird; Bucci; Markovits; O’Brien, Costa, Overton; Dias, apud Dias, Spinillo, 1996) também limitam o uso da noção do raciocínio dedutivo, destacado das condições de relação com o conteúdo das premissas. Como Colinvaux ( 1 996) nos mostra, em seu artigo, a pretensão da lógica formal de destacar das proposições tratadas como premissas o significado destas é contraditório à noção que temos da constituição da linguagem e do discurso. Ainda citando Bakhtin ( 1992), a palavra é o signo ideológico por excelência, que não pode ser analisado separadamente das condições materiais na qual é produzida. Nisso reside a materialidade da língua: constitutiva dos modos de ação e de elaboração mental, como práticas inscritas e instituídas na cultura.

A não separação, pelos sujeitos da pesquisa, dos seres, das relações e dos signos, revela uma cosmovisão integrativa, relacional, na qual constroem suas ações, relações, e elaborações mentais/discursivas. É um movimento interativo, no qual o sujeito traz, para o ato do discurso, sua posição sócio-histórica e a complexidade de um real organizado pelo princípio da inter-relação, que nos é revelado sob a forma de indícios em sua linguagem.

5. Sendo, portanto, uma das autoras que trouxeram à luz os estudos de Luria no Brasil. 
Quais as conseqüências desta breve análise? Em primeiro lugar, ao desconsiderar o que os sujeitos da pesquisa trazem em seus enunciados, podemos dizer que os resultados apontados pela pesquisa de Luria são, em última análise, uma descrição monológica da fala do outro. Conseqüentemente, a voz última do pesquisador, presa a seu paradigma, silencia a gama de possibilidades de formas racionais devido a sua incapacidade de reconhecê-las naquele momento social e histórico. O pesquisador aponta como incapacidade cognitiva o que na realidade foi a própria incapacidade de olhar e ouvir o outro, contribuindo desta forma para a construção social de uma visão depreciativa daquele sujeito e, conseqüentemente, para a criação e manutenção de distinções que corroboram a exclusão dos sujeitos não alfabetizados do "lugar do legítimo".

A segunda conseqüência é um olhar homogeneizador, contemporâneo de uma modernidade e de suas já discutidas implicações, que tenta enquadrar em seus pressupostos os dados que o real revela, deixando uma etiqueta de não tudo que escapa a seus critérios. Os resultados de tais ações são um fortalecimento de uma minoria dita hegemônica, e um empobrecimento não só das alternativas sociais dos sujeitos que ficam excluídos, a partir destes critérios, mas de todo um coletivo humano, pela não consideração de uma situação diversa que, se acreditarmos numa perspectiva dialética das relações humanas e do conhecimento, é possibilitadora do avanço, do crescimento. Representa uma perdana medida em que é um empobrecimento das alternativas possíveis.

A questão aqui, voltamos a repetir, é a do enfoque do olhar do pesquisador. Uma perspectiva de análise dos processos mentais de adultos não alfabetizados não pode prescindir de uma abertura, no sentido do entendimento de que os processos racionais podem apresentar-se de muitas formas, e que essas formas têm profunda relação com as práticas na cultura, que são sócio-históricas. No caso da pesquisa de Luria, pudemos aprender que, invertendo a perspectiva do olhar, potencializamos os sujeitos, reconhecendo neles modos de ser, fazer, dizer, pensar legítimos. Formas inclusive que buscamos para libertarmo-nos dos dualismos característicos do paradigma de nossa cultura moderna ocidental.

Acreditamos que para isso será necessário romper com modelos preestabelecidos de análise, reconhecendo o rea/em sua complexidade. Cremos que todos nós, que falamos do ponto de vista da ciência, temos uma semelhança errada com o personagem de Cervantes. Talvez o que nos falte é nos aproximarmos de um D. Quixote sem Cervantes; aquele que é capaz de subverter o real em nome do que é possível, além das "evidências". Mas acreditamos que essa aventura, da qual esta releitura é apenas uma parte, nos ajudará, no sentido de apontar alguns caminhos para aprendermos a arte de subverter-a nós mesmos, se preciso for - para potencializar e revelar a contemporaneidade na diversidade, e a complexidade do universo dos seres humanos e suas culturas. 


\section{REFERÊNCIAS BIBLIOGRÁFICAS}

BAKHTIN, M. Marxismo e filosofia da linguagem. São Paulo: Hucitec, 1992.

BENJAMIN, W. Magia e técnica, arte e política: ensaios sobre literatura e história da cultura. São Paulo: Brasiliense, 1994. (Obras escolhidas, v. I)

CERTEAU, M. de. A invenção do cotidiano: artes de fazer. Petrópolis: Vozes, 1994.

CERVANTES SAAVEDRA, M. Dom Quixote de la Mancha. São Paulo: Abril Cultural, 1978.

COLINVAUX, D. Concept formation: from logical classes to meaning provinces. [llnd. Conference for Socio-cultural Research - University of Geneva, Geneva, 1996.]

DIAS, M. B. B., SPINILLO, A. G. (orgs.) Tópicos em psicologia cognitiva. Recife: Ed. da UFPE, 1996.

GINZBURG, C. Mitos, emblemas e sinais. morfologia e história. São Paulo: Companhia das Letras, 1991.

LURIA, A. R. Desenvo/vimento cognitivo: seus fundamentos culturais e sociais. São Paulo: Ícone, 1990.

NEWMAN, D., GRIFFIN, P., COLE, M. La zona de construcción del conocimiento. Madrid: Morata, 1991.

PERELMAN, C., OLBRECHTS-TYTECA, L. Tratado da argumentação: a nova retórica. São Paulo: Martins Fontes, 1996.

ROJO, R. H. R. Enunciação e interação na ZDP: do non sense à construção dos gêneros de discurso. In: ENCONTRO SOBRE TEORIA E PESQUISA EM ENSINO DE CIÊNCIAS. Anais... Belo Horizonte: Faculdade de Educação da UFMG, 1997. p.95- 109.

TFOUNI, L. V. Adultos não alfabetizados. o avesso do avesso. Campinas: Pontes, 1988. 